\title{
Residues of synthetic pyrethroid pesticides in vegetables, fruit, sediment and water from an intensive agricultural area (Fang district, Chiang Mai, Thailand)
}

\author{
N. Pakvilai ${ }^{1,2,6}$, T. Prapamontol ${ }^{2}$, P. Thavornyutikarn ${ }^{3}$, \\ A. Mangklabruks ${ }^{4}$, S. Chantara ${ }^{3} \&$ C. Santasup ${ }^{5}$ \\ ${ }^{1}$ Environmental Science PhD Program, Chiang Mai University, Thailand \\ ${ }^{2}$ Research Institute for Health Sciences (RIHES), \\ Chiang Mai University, Thailand \\ ${ }^{3}$ Faculty of Science, Chiang Mai University, Thailand \\ ${ }^{4}$ Faculty of Medicine, Chiang Mai University, Thailand \\ ${ }^{5}$ Faculty of Agriculture, Chiang Mai University, Thailand \\ ${ }^{6}$ Faculty of Science, Valaya Alongkorn Rajabhat University, Thailand
}

\begin{abstract}
This study was conducted in four intensive agricultural areas of the Fang district, Chiang Mai, northern Thailand. The objective of this study was to determine synthetic pyrethroid residues in vegetable, fruit, sediment, and surface water samples. Fruit and vegetables were purchased from local markets in the study areas. The vegetables in this study included cabbage, kale, water spinach, cauliflower, Chinese cabbage, Chinese mustard, yard long bean, cucumber, and sugar pea, while the fresh fruit included tangerine, guava, apple, dragon fruit, mango, sand pear, rose apple, lychee and grape. Sediment and surface water samples were collected from main streams of the four studied areas. The pyrethroid residues in vegetables, fruit, and sediment samples were extracted with dichloromethane in an ultrasonic bath and cleaned up on a graphite carbon cartridge. Liquid - liquid extraction technique was used to prepare pyrethroid compounds from surface water samples. The extracted samples were determined by using gas chromatography - electron capture detection (GC-ECD). Six synthetic pyrethriod pesticides in this study consist of lambda cyhalothrin, permethrin, cyfluthrin, cypermethrin, fenvalerate, and deltamethrin.
\end{abstract}


Cypermethrin was found to be the highest detection percentage in surface water, vegetables, and fruit samples at 33.3, 75.8 and 95.3\%, respectively. Meanwhile, permethrin was the highest detection percentage in sediment samples at $66 \%$. However, lambda cyhalothrin was detected in sediment and surface water samples with the highest levels at 0.38 and $1.61 \mathrm{mg} / \mathrm{kg}$, respectively. Deltamethrin was detected in vegetable samples with the highest level at $9.97 \mathrm{mg} / \mathrm{kg}$ and cypermethrin was detected in fruit samples with the highest level at $11.83 \mathrm{mg} / \mathrm{kg}$. Furthermore, this study is an application of the developed method providing a high sensitivity with the limit of detection (LoD) of permethrin at $0.11 \mathrm{mg} / \mathrm{kg}$, cyfluthrin at $0.11 \mathrm{mg} / \mathrm{kg}$, fenvalerate at $0.22 \mathrm{mg} / \mathrm{kg}$, lambda cyhalothrin at $0.26 \mathrm{mg} / \mathrm{kg}$, cypermethrin at $0.51 \mathrm{mg} / \mathrm{kg}$ and deltamethrin at $0.65 \mathrm{mg} / \mathrm{kg}$.

Keywords: synthetic pyrethroid pesticides, intensive agricultural area, northern Thailand.

\section{Introduction}

The tendency of pesticide usage has been increasing worldwide due to the expansion of pesticide-based mono-cropping agriculture either for food or for energy. After the 1990s the usage of highly toxic and persistent pesticides were reduced by the implementation of regulations. Most of organochlorine pesticides have been banned because of their high persistence in the environment, bioaccumulation through the food chain, and risk in causing harmful effects on wildlife and humans.

Synthetic pyrethroid pesticides are the most frequently used in agricultural application, residential areas and commercial facilities [1]. There is a new group of pesticides which has similar chemical formula to pyrethrum [2]. It has greater photostability, enhanced insecticidal activity, and relatively low toxicity when compared to organochlorine and organophosphate pesticides. Synthetic pyrethroid pesticides are non-systemic as they cannot penetrate into the plant. The extraction of these pesticides is rather simple compared to the systemic organophosphate and carbamate pesticides because they form a deposit on the surface of the leaf after treatment. In Thailand, a great amount of pesticides have been imported and the active chemical ingredient has continued to increase from 60,541 tons in 2001 to 117,698 tons in 2010 . The use of synthetic pyrethroid pesticides is approximately $5-7 \%$ of the total amount of pesticides used in Thailand [3]. They are widely used in growing fruit and vegetables and these chemicals are accumulated in the environment such as water streams and soil sediments $[4,5]$. This paper focused on synthetic pyrethroid residues in fruit, vegetables, sediment, and surface water of the Fang district, an intensive agricultural area of the Chiang Mai province, northern Thailand.

\section{Experiments}

\subsection{Study area}

This study was conducted in an intensive agricultural community in the Fang district, Chiang Mai province, northern Thailand $\left(19^{\circ} 47^{\prime} 00.86^{\prime \prime} \mathrm{N}\right.$ latitude and 
$99^{\circ}$ 03' 14.64" S longitude). The study areas for sediment and surface water sampling were located in Mon Pin subdistrict (20 06' 22.93" N 99 05' 02.08" S),

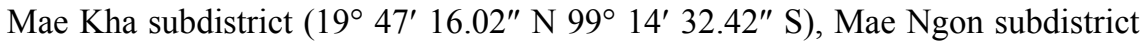
$\left(19^{\circ} 46^{\prime} 34.87^{\prime \prime} \mathrm{N} 99^{\circ} 05^{\prime} 51.70^{\prime \prime} \mathrm{S}\right)$, and Wiang subdistrict $\left(19^{\circ} 50^{\prime} 44.79^{\prime \prime} \mathrm{N} 99^{\circ}\right.$ $\left.20^{\prime} 18.68^{\prime \prime} \mathrm{S}\right)$.

\subsection{Experimental}

\subsubsection{Reagent and calibration}

Standard reagents for calibration in this study consist of lambda cyhalothrin, bifenthrin (as an internal standard), permethrin, cyfluthrin, cypermethrin, fenvalerate and deltamethrin, with a different range of purity from 92.5 to $99.5 \%$ (Dr. Ehrenstorfer, Augsburg, Germany). Methylene chloride and ethyl acetate were both organic residue analysis graded from J.T. beaker (Philipsburg, NJ, USA) and used for extraction and solvation. Anhydrous sodium sulfate was obtained from Merck (Germany). Standard stock solution was prepared in ethyl acetate and stored at $-20^{\circ} \mathrm{C}$. Intermediate and working standard solutions of a mixture of synthetic pyrethroid pesticides and internal standard solution was prepared in ethyl acetate. The standard solutions were prepared at 5, 10, 20, 100, $150,200,250$ and $300 \mathrm{ng} / \mathrm{mL}$.

\subsubsection{Instrumental analysis}

The samples were analyzed by Gas Chromatography with Electron Capture Detector (GC-ECD, HP6890 series, USA). The separation was accomplished by capillary column, HP-5 (5\% phenylmethylpolysiloxane phase with $30 \mathrm{~m} \times$ $0.25 \mathrm{~mm}, 0.25 \mu \mathrm{m}$ film thickness). Injection was operated in the splitless mode. The injection port and detector temperature were set at $250^{\circ} \mathrm{C}$ and $300^{\circ} \mathrm{C}$, respectively. The HP-5 column temperature was chronologically adjusted as follows: the initial sample temperature of $100^{\circ} \mathrm{C}$ was increased at the rate of $15^{\circ} \mathrm{C} / \mathrm{min}$ to $250^{\circ} \mathrm{C}$ and the sample was detained for $1 \mathrm{~min}$ at $250^{\circ} \mathrm{C}$. After that, the sample was heated up from $250^{\circ} \mathrm{C}$ to $280^{\circ} \mathrm{C}$ at the rate of $5^{\circ} \mathrm{C} / \mathrm{min}$ and held for $3 \mathrm{~min}$ at the final temperature. Helium (99.994\% purity) at flow rate of $1.5 \mathrm{~mL} / \mathrm{min}$ was used as the gas carrier. GC-ECD make-up gas for ECD was OFN (99.999\% purity) flow rate at $14.7 . \mathrm{mL} / \mathrm{min}$.

\subsection{Sampling}

\subsubsection{Vegetable and fruit samples}

Fruit and vegetables were purchased from local markets in four sub districts of the studied areas. The vegetables in this study included cabbage, kale, water spinach, cauliflower, Chinese cabbage, Chinese mustard, yard long bean, cucumber, and sugar pea, while the fresh fruit included tangerine, guava, apple, dragon fruit, mango, sand pear, lychee, rose apple and grape. The sample weight was at least one kilogram for small and medium sized fresh produce and two kilograms for large size fresh produce [6]. In addition, the samples of pears, oranges and apples were purchased for ten each. One kilogram 
of the collected vegetables and fruit were quartered and half of them were randomly selected (approximately 500 grams) to homogenize by blender (IKA ULTRA-TURRAX T25 digital, Germany). Then, 50 grams aliquot of blended sample was kept and reserved in a plastic container at a temperature of $-20^{\circ} \mathrm{C}$ prior to analysis.

\subsubsection{Sediment and surface water samples}

Sediment and surface water samples were collected at ten different sites within the main streams of four sub districts during August-September 2009. Sediments which collected from depositional zone were wrapped with foil and placed in zip lock plastic bags. Sediments were air dried at room temperature, ground and graded through a metal sieve (35 mesh). Large-volume of surface water samples were collected by Kemmerer water sample at 20 centimetres deep and kept in pre-cleaned PETE plastic bottles.

\subsection{Sample treatment and extraction}

\subsubsection{Vegetable, fruit, and sediment extraction and clean-up}

Five grams of sample was loaded into $50 \mathrm{~mL}$ Teflon centrifuge tube and extracted with $10 \mathrm{~mL}$ dichloromethane (DCM) for 30 seconds with a vortex mixer. The mixture was further extracted in an ultrasonicate bath for $5 \mathrm{~min}$ and re-extracted with $10 \mathrm{ml}$ DCM with vortex for 30 seconds. The whole samples were filtrated through a glass funnel with Whatman No.1 filter paper and passed onto $50 \mathrm{~mL}$ centrifuge tube. The extract was transferred onto the $250 \mathrm{mg}$ graphite carbon clean up column and eluted with $8 \mathrm{ml} \mathrm{DCM}$, drop by drop, in a $15 \mathrm{~mL}$ graduated test tube. Extracts were evaporated to dry off by rotary evaporation at $37^{\circ} \mathrm{C}$ under reducing pressure. The final volume of concentrated extract was $1 \mathrm{~mL}$ with ethyl acetate and determined by gas chromatography with electron capture detection [7-11].

\subsubsection{Surface water extraction}

Each of the water samples was loaded into a separating funnel for $50 \mathrm{~mL}$ then 30 grams of sodium chloride was added and shaken with $50 \mathrm{~mL}$ dichloromethane/ethyl acetate $(1: 1, \mathrm{v} / \mathrm{v})$. The solvent extraction procedure was repeated twice. The extracted solution was filtered with sodium sulphate and evaporated under vacuum rotary evaporation at $37^{\circ} \mathrm{C}$ until about $2 \mathrm{~mL}$ and driedoff using a stream of nitrogen gas. The final volume of the solution was adjusted to $1 \mathrm{~mL}$ with ethyl acetate prior to gas chromatography with electron capture detection $[5,12,13]$.

\section{Results and discussion}

This monitoring study was conducted in vegetables, fruit, surface water and sediment of four sites in the agricultural area of the Fang district where synthetic pyrethroid pesticides were vastly applied throughout the year and really need at least a reference here. 


\subsection{Synthetic pyrethroid residues in vegetables and fruit}

Table 1 shows the common name, scientific name, and synthetic pyrethroid residues which have been found in the vegetable and fruit samples analyzed. The vegetable residue samples showed the pesticide ranging between 30.8 to $100 \%$ of samples analyzed while the fruit samples were detected $100 \%$. In most of the vegetable samples one or more residues were detected at $100 \%$, except cucumber, Chinese cabbage, and cabbage which found 30.8, 88.9, and 92.3\% respectively.

Table 1: $\quad$ Name of sample and incidence of pyrethroid residues in vegetables and fruit.

\begin{tabular}{|c|c|c|c|}
\hline $\begin{array}{l}\text { Common } \\
\text { name }\end{array}$ & Scientific name & $\begin{array}{c}\text { No. of } \\
\text { samples }\end{array}$ & $\begin{array}{c}\% \text { samples } \\
\text { with one or } \\
\text { more residues }\end{array}$ \\
\hline \multicolumn{4}{|c|}{ Vegetable $\mathrm{N}=66$} \\
\hline Cabbage & Brassica oleracea L. var. capitata & 13 & 92.3 \\
\hline Kale & Brassica oleracea L.var.acephala DC. & 8 & 100 \\
\hline $\begin{array}{c}\text { Water } \\
\text { spinach }\end{array}$ & Impomoea aquatica Forsk. & 2 & 100 \\
\hline Cauliflower & Brassica oleracea L.var.botrytis L. & 3 & 100 \\
\hline $\begin{array}{l}\text { Chinese } \\
\text { cabbage }\end{array}$ & $\begin{array}{l}\text { Brassica rapa L. subsp. pekinensis } \\
\text { (Lour.) Olsson. }\end{array}$ & 9 & 88.9 \\
\hline $\begin{array}{l}\text { Chinese } \\
\text { mustard }\end{array}$ & $\begin{array}{l}\text { Brassica.camprestris L. ssp. Chinensis } \\
\text { (Lour.) Ruprecht. }\end{array}$ & 5 & 100 \\
\hline $\begin{array}{l}\text { Yard long } \\
\text { bean }\end{array}$ & $\begin{array}{l}\text { Vigna unguiculata var. sesquipedalis } \\
\text { (Vigna sinensis var. sesquipedalis L. } \\
\text { Verdc.) }\end{array}$ & 10 & 100 \\
\hline Cucumber & Cucumis sativus $\mathrm{L}$. & 13 & 30.8 \\
\hline Sugar pea & Pisum sativum var.macrocarpon Ser. & 3 & 100 \\
\hline \multicolumn{4}{|c|}{ Fruit $\mathrm{N}=55$} \\
\hline Tangerine & Citrus reticulate & 10 & 100 \\
\hline Guava & Psidium guajava & 2 & 100 \\
\hline Apple & Malus domestica & 7 & 100 \\
\hline Dragon fruit & Hylocereu undatuss & 5 & 100 \\
\hline Mango & Mangifere india Linn. & 5 & 100 \\
\hline Sand pear & Pyrus pyrifolia & 3 & 100 \\
\hline Grape & Vitis venefera & 2 & 100 \\
\hline Lychee & Litchi chinensis Sonn. & 5 & 100 \\
\hline Rose apple & $\begin{array}{c}\text { Syzygium samarangense (Blume) } \\
\text { Merr.\&L.M.Perry }\end{array}$ & 3 & 100 \\
\hline
\end{tabular}


The mean level of pyrethroid pesticides in vegetable and fruit samples is presented in table 2. Cypermethrin has the highest positive sample at 50 samples of vegetable and 43 samples of fruit. The result also shows the highest mean value of cypermethrin in fruit at $0.854 \mathrm{mg} / \mathrm{kg}$., while deltamethrin shows the highest mean value in vegetables at $0.874 \mathrm{mg} / \mathrm{kg}$. In addition, the mean value of others pesticides in vegetables are $0.374 \mathrm{mg} / \mathrm{kg}$ of lambda cyhalothrin, 0.219 $\mathrm{mg} / \mathrm{kg}$ of fenvalerate, $0.111 \mathrm{mg} / \mathrm{kg}$ of cyfluthrin and $0.065 \mathrm{mg} / \mathrm{kg}$ of permethrin. The following mean value of pesticide in fruit samples from cypermethrin are deltamehrin $(0.420 \mathrm{mg} / \mathrm{kg})$, fenvalerate $(0.323 \mathrm{mg} / \mathrm{kg})$, lambda cyhalothrin $(0.156 \mathrm{mg} / \mathrm{kg})$, cyfluthrin $(0.129 \mathrm{mg} / \mathrm{kg})$, and permethrin $(0.115 \mathrm{mg} / \mathrm{kg})$.

Table 2: $\quad$ Mean levels of six synthetic pyrethroid residues in vegetable and fruit samples in Fang district ( $\mathrm{mg} / \mathrm{kg}$ fresh weight).

\begin{tabular}{|c|c|c|c|c|}
\hline \multirow{2}{*}{ Pesticide } & \multicolumn{2}{|c|}{ Vegetable $(\mathrm{n}=66)$} & \multicolumn{2}{c|}{ Fruit $(\mathrm{n}=43)$} \\
\cline { 2 - 5 } & $\begin{array}{c}\text { Mean value } \\
(\mathrm{mg} / \mathrm{kg})\end{array}$ & $\begin{array}{c}\text { No. of } \\
\text { positive } \\
\text { samples }\end{array}$ & $\begin{array}{c}\text { Mean } \\
\text { value } \\
(\mathrm{mg} / \mathrm{kg})\end{array}$ & $\begin{array}{c}\text { No. of } \\
\text { positive } \\
\text { samples }\end{array}$ \\
\hline lambda cyhalothrin & 0.374 & 25 & 0.156 & 20 \\
\hline permethrin & 0.065 & 32 & 0.115 & 31 \\
\hline cyfluthrin & 0.111 & 47 & 0.129 & 34 \\
\hline cypermethrin & 0.530 & 50 & 0.854 & 43 \\
\hline fenvalerate & 0.219 & 38 & 0.323 & 33 \\
\hline Deltamethrin & 0.874 & 41 & 0.420 & 25 \\
\hline
\end{tabular}

According to the Thai Agricultural Commodity and Food Standard (2006), the maximum residue levels (MRLs) of pesticide were varies by commodities as shown in table 3 . The mean values of pesticide in most samples were generally exceeding the MRLs, except cypermethrin in cabbage, fenvalerate in mango and deltamethrin in yard long bean. The highest percentage was found in cypermethrin of sugar pea while deltamethrin of yard long bean showed the lowest percentage. Furthermore, the percentage of sample above MRLs of different international standard has been presented in table 4. Samples with permethrin were not detected when compared to the Codex MRLs. Percentage of the samples above MRLs of Codex and Thailand have similar trend in all pesticides with range from 4.6 to $19.3 \%$. In addition, the European standards which have a lower concentration limit show a higher percentage of sample exceed the MRLs in the range of 22 to $55 \%$. 
Table 3: The MRLs of pesticide in commodities and number of samples above MRLs.

\begin{tabular}{|c|c|c|c|c|}
\hline \multirow{2}{*}{ Pesticide } & Commodities & $\begin{array}{c}\text { Mean } \\
\text { value } \\
(\mathrm{mg} / \mathrm{kg})\end{array}$ & $\begin{array}{c}\text { MRLs } \\
(\mathrm{mg} / \mathrm{kg})\end{array}$ & $\begin{array}{c}\text { Percentage } \\
\text { of samples } \\
\text { above MRLs }\end{array}$ \\
\hline Lambda cyhalothrin & Cabbage & 0.327 & 0.2 & 23.1 \\
\cline { 2 - 5 } & Cauliflower & 0.273 & 0.2 & 66.7 \\
\hline \multirow{4}{*}{ Cypermethrin } & Cabbage & 0.087 & 0.1 & 30.8 \\
\cline { 2 - 5 } & Yard long bean & 0.810 & 0.05 & 80.0 \\
\cline { 2 - 5 } & Sugar pea & 0.751 & 0.05 & 100.0 \\
\cline { 2 - 5 } & Chinese cabbage & 1.962 & 1 & 40.0 \\
\hline Fenvalerate & Mango & 0.408 & 1 & 20.0 \\
\hline Deltamethrin & Cabbage & 0.838 & 0.2 & 76.9 \\
\cline { 2 - 5 } & Kale & 1.770 & 0.5 & 62.5 \\
\cline { 2 - 5 } & Yard long bean & 0.192 & 0.2 & 10.0 \\
\cline { 2 - 5 } & Cauliflower & 0.478 & 0.1 & 33.3 \\
\cline { 2 - 5 } & Chinese mustard & 1.962 & 0.5 & 33.3 \\
\hline
\end{tabular}

${ }^{\mathrm{a}}$ Thai Agricultural Commodity and Food Standard (2006).

\subsection{Synthetic pyrethroid pesticides in sediment and surface water}

More detail about pesticide detected in sediment and surface water was presented in table 5. Synthetic pyrethroids were found in both sediment surface water samples. The overall frequency of occurrence in sediment of all sites are $66.7 \%$ in permethrin, $64.1 \%$ in cypermethrin, $51.3 \%$ in fenvalerate, $25.6 \%$ in cyfluthrin, $23.1 \%$ in lambda cyhalothrin and $12.8 \%$ in deltamethrin. There were no detections in sediment of lambda cyhalothrin in Mae Ngon and Mon Pin sites, and deltamethrin in Wieng site. The overall frequency of occurrence in surface water of all sites are $33.3 \%$ in cypermethrin, $30.8 \%$ in fenvalerate, $28.2 \%$ in permethrin $12.8 \%$ in cyfluthrin lambda, $5.1 \%$ in lambda cyhalothrin and $2.6 \%$ in deltamethrin. There were no detections in surface water of lambda cyhalothrin, and deltamethrin in the Mae Kha, Mon Pin, and Wieng sites.

\section{Conclusion}

From this study, synthetic pyrethroid residues were found in vegetables, fruit sediment and surface water samples. The data performed showed $32.1 \%$ of all samples exceeded the maximum residue limits which indicate that synthetic pyrethroid pesticides were contaminated to sediment and surface water from their wide usage in agriculture. In addition, the standards of permethrin and 


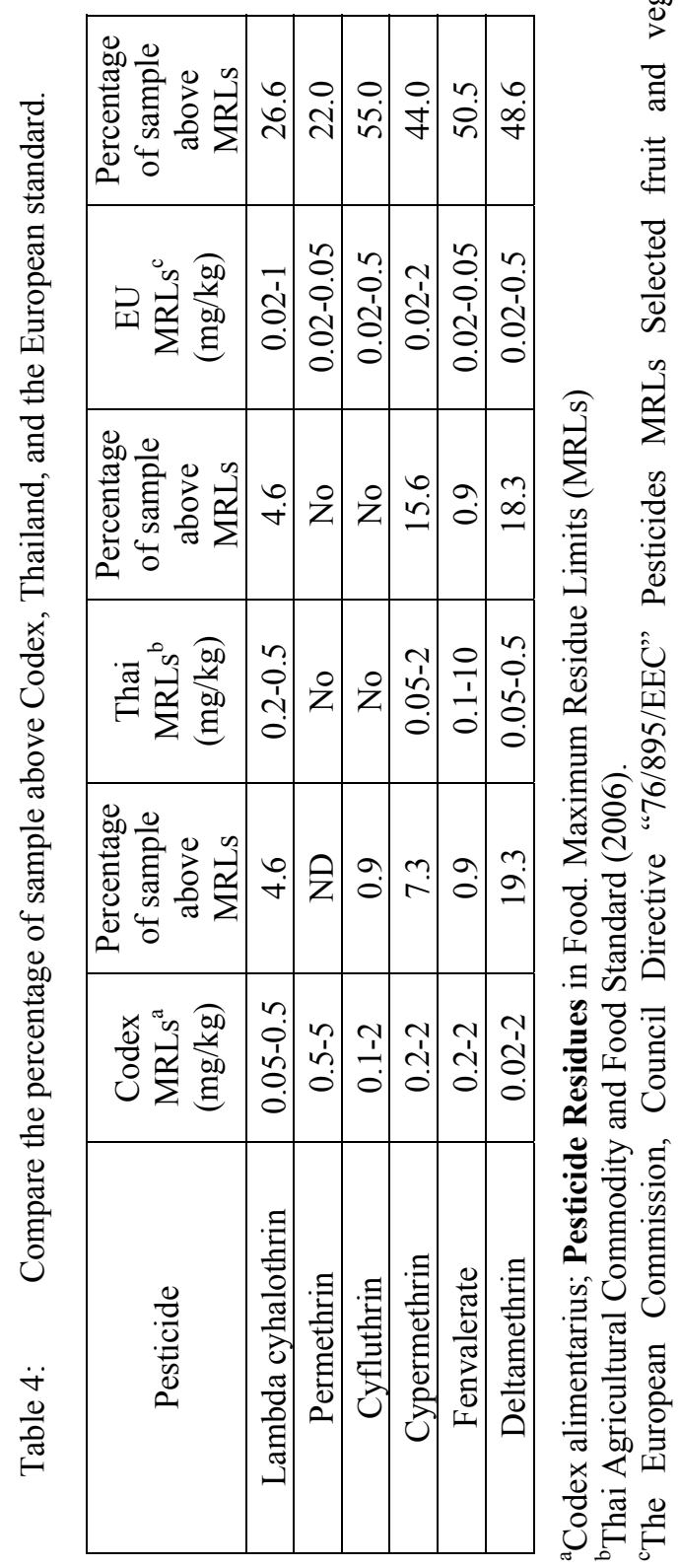


Table 5: $\quad$ Mean concentration $(\mathrm{mg} / \mathrm{kg})$ and percentage of pesticide residues in sediments and surface water.

\begin{tabular}{|c|c|c|c|c|}
\hline \multirow{2}{*}{ Pesticide } & \multicolumn{2}{|c|}{ Sediment $(\mathrm{N}=39)$} & \multicolumn{2}{c|}{ Surface water $(\mathrm{N}=39)$} \\
\cline { 2 - 5 } & $\begin{array}{c}\text { Mean } \\
\text { value } \\
(\mathrm{mg} / \mathrm{kg})\end{array}$ & $\mathrm{N}(\%)$ & $\begin{array}{c}\text { Mean value } \\
(\mathrm{mg} / \mathrm{kg})\end{array}$ & $\mathrm{N}(\%)$ \\
\hline lambda cyhalothrin & 0.058 & $9(23.1)$ & 0.813 & $2(5.1)$ \\
\hline permethrin & 0.055 & $26(66.7)$ & 0.388 & $11(28.2)$ \\
\hline cyfluthrin & 0.015 & $10(25.6)$ & 0.196 & $5(12.8)$ \\
\hline cypermethrin & 0.042 & $25(64.1)$ & 0.296 & $13(33.3)$ \\
\hline fenvalerate & 0.028 & $20(51.3)$ & 0.291 & $12(30.8)$ \\
\hline deltamethrin & 0.066 & $5(12.8)$ & 0.029 & $1(2.6)$ \\
\hline
\end{tabular}

cyfluthrin in Thailand have not been provided for the control of contamination in fruit and vegetable. Contaminations can affect human health in the case of high accumulation and economic race such as agriculture produce's price and exporting barrier. Furthermore, the Thailand government should be restricted in the usage of synthetic pyrethroid pesticides.

\section{References}

[1] Heudorf, U., Butte, W., Schulz, C., \& Angerer, J., Reference values for metabolites of pyrethroid and organophosphorous insecticides in urine for human biomonitoring in environmental medicine. Int.J Hyg Environ Health, 209(3), pp.293-299, 2006.

[2] Elliott, M. \& Janes, N. F., Pyrethrum the Natural Insecticide, 1973.

[3] Office of Agricultural Economics., Quantity and value of agricultural exports, $2004-2005,2006$.

[4] Adeyeye, A. \& Osibanjo, O., Residues of organochlorine pesticides in fruits, vegetables and tubers from Nigerian markets. The Science of The Total Environment, 231(2-3), pp. 227-233, 1999.

[5] Casas, V., Llompart, M., Garca-Jares, C., Cela, R., \& Dagnac, T., Multivariate optimization of the factors influencing the solid-phase microextraction of pyrethroid pesticides in water. Journal of Chromatography A, 1124(1-2), pp.148-156, 2006.

[6] Codex Alimentarius., Food Standards Programme. Pesticide Residues in Food. Method of analysis and sampling. Volume 2A Part I, World Health Organization, 2000.

[7] Stajnbaher, D. \& Zupancic-Kralj, L., Multiresidue method for determination of 90 pesticides in fresh fruits and vegetables using solidphase extraction and gas chromatography-mass spectrometry. J Chromatogr.A, 1015(1-2), pp.185-198, 2003. 
[8] Zawiyah, S., Che Man, Y.B., Nazimah, S.A.H., Chin, C.K., Tsukamoto, I., Hamanyza, A.H., \& Norhaizan, I., Determination of organochlorine and pyrethroid pesticides in fruit and vegetables using SAX/PSA clean-up column. Food Chemistry, 102(1), pp.98-103, 2007.

[9] Zhang, B., Pan, X., Venne, L., Dunnum, S., McMurry, S.T., Cobb, G.P., \& Anderson, T.A., Development of a method for the determination of 9 currently used cotton pesticides by gas chromatography with electron capture detection. Talanta, 75(4), pp.1055-1060, 2008.

[10] Motohashi, N., Nagashima, H., Pbrkbnyi, C., Subrahmanyam, B., \& Zhang, G.W., Official multiresidue methods of pesticide analysis in vegetables, fruits and soil. Journal of Chromatography A, 754(1-2), pp.333-346, 1996.

[11] Kaushik, N. \& Handa, S., New clean-up method for gas chromatographic analysis of pyrethroid residues. Chromatographia, 46(3), pp. 209-212, 1997.

[12] Ayas, Z., Barlas, N., \& Kolankaya, D.r., Determination of organochlorine pesticide residues in various environments and organisms in Goksu Delta, Turkey. Aquatic Toxicology, 39(2), pp.171-181, 1997.

[13] Barri, T., Bergstrom, S., Hussen, A., Norberg, J., \& Jonsson, J., Extracting Syringe for determination of organochlorine pesticides in leachate water and soil-water slurry: A novel technology for environmental analysis. Journal of Chromatography A, 1111(1), pp.11-20, 2006. 